MATEC Web of Conferences 45, 04001 (2016)

DOI: $10.1051 /$ matecconf/20164504001

C Owned by the authors, published by EDP Sciences, 2016

\title{
A development of the method of the control signal formation for the hot plate mill automation systems to improve the flatness of the finish plate
}

\author{
Stanislav S. Voronin, Vadim R. Gasiyarov, Andrey A. Radionov \\ South Ural State University (National Research University), 454080, Lenin ave. - 76, Chelyabinsk, Russian Federation
}

\begin{abstract}
This article describes how to control of the hot plate mill automation system to improve the quality metrics if the final strip. Based on the data of the modern hot rolling mills the classification of the cage equipment was designed. Depending on the degree of influence on the magnitude of reduction, the equipment was divided into categories. The functioning of every system including the main and the vertical cages was described. The conditions of electrical and hydraulic mechanisms was marked. The developed algorithm allows to improve defects based on the finite number of the thickness measurements given by special non-contact sensors. The example of regulators signals calculating was shown. The result of the algorithm operating was illustrated.
\end{abstract}

\section{Introduction}

The requirements for geometric parameters of the finished rolling strip is growing year per year, not depending on product assortment of the hot plate mills. To satisfy all specifications of the plate flatness concerning the four-high mill stand "quarto" a number of special control systems were designed and constructed by engineers and scientists around the world. This systems help to hold the roll gap in a given range during all the rolling process.

The main goal of the rolling stand automation system is signal formation for local regulators of the every flatness control system. In other case the displacement of the thickness and width on the final rolled strip may occur. To escape this problem it is necessary to develop a new algorithm of the formation of control signal for automation systems of the hot plate mill.

\section{Classification of flatness control systems of the hot plate mill}

All the flatness control systems can be divided into two groups: the main group and the auxiliary group [1]. The main group includes equipment to form an initial roll gap, including rough tuning and gap correction at the rolling moment. Equipment of the auxiliary group systems may be different, depends on the type of rolling mill [2]. This group is responsible for the accurate thickness adjustment along the strip. Thickness deviation arise from the two basic reasons.

The first reason is a number of external factors that make an additional value to previously exposed roll gap [3]. The work roll bending under the metal pressure, the rolls wear and thermal expansion, the backlashes and deformations of the roll stand - this are some of the external factors. It is necessary to take into consideration all the factors to offset their negative impact. Some values could be determined by computer modelling before rolling. Based on the model results the settings of the auxiliary control systems are performed.

The second reason is a thickness deviation in every measurement point along the slab before rolling process. Moreover, the slab often has internal defects, obtained at the casting stage, which can make a bad impact on the final strip. In this case, some auxiliary control systems put into work during rolling. All systems conditions are determined by sensors, which help to know about metal thickness every rolling moment. Some systems also perform an active role in a case of the rolling with different thickness along the strip. Typical classification of flatness control systems of the hot plate mill is shown at figure 1 .

Every flatness control system must provide both separately mode and simultaneously mode with other systems. Electromechanical gap control system (EGCS) moves only between passes, that is when there is no a plate in the rolling stand [4]. Roll system can move in a vertical plane via rotating of screw-down mechanism. EGCS allows changing the gap in wide range (several hundred millimeters). At the modern rolling mills, EGCS consist of two pressure screws to change the roll gap at the edges of the plate. Every pressure screw is driven by own electric motor. To provide stable feedback it is necessary to use screw-setting transducers.

Hydraulic gap control system (HGCS) is designed to accurate correction of the roll gap. HGCS activates during the rolling process. Hydraulic system includes two cylinders that are moved by own servo valve, which changes amount and moving direction of the hydraulic 
fluid [5]. Actual position is calculated by averaging feedback signals from two position-sensitive transducers. Rolling pressure is determined via special load cells.

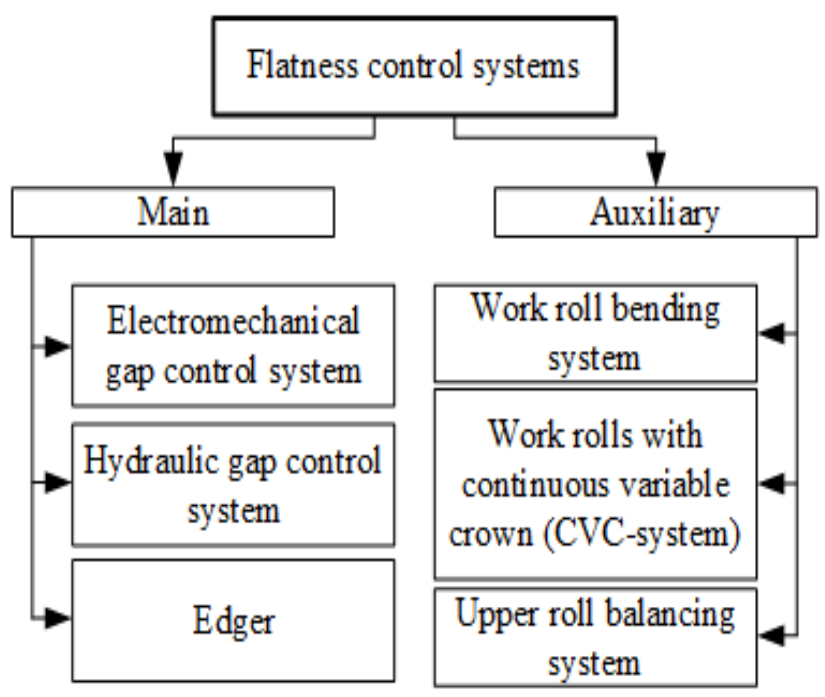

Figure 1. Flatness control system classification

Vertical cage (edger) has own control subsystems like EGCS, HGCS, width control system (WCS), roll balancing system [6]. Operation of these subsystems is similar with main cage.

Work roll bending system (WRBS) is needed to compensate rolls bending cases by high-pressure level at reducing moments [7]. The bending value depends on the rolling pressure, plate width, type of the rolls. WRBS helps to minimize thickness variation along the plate width by compensation the bending forces between metal plate and work rolls. Bending system uses four hydraulic cylinders (eight cylinders total) by each side (figure 2).

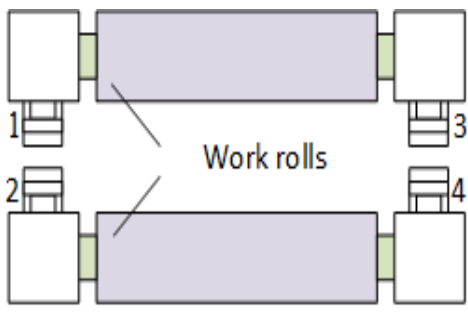

Front view

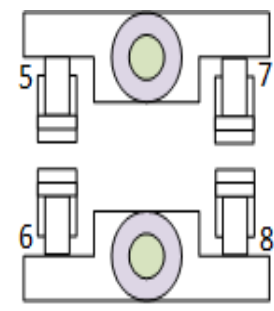

Side view
Figure 2. Arrangement of the hydraulic cylinders

Another auxiliary system to improve cross thickness is CVC-system. Work rolls have S-type polish with same contour and moving in horizontal plane between rolling passes. The value of the rolls shift influences on the roll force in the center and at the edges of the plate. Four hydraulic cylinders are used to shift upper and lower work roll. The shift value is limited by cylinder stroke and controlled by position sensors built-in each cylinder.

Upper roll balancing system (RBS) is used to minimize backlashes between rolls and stand. RBS has hydraulic and mechanical blocking device to hold upper roll at given level.

\section{Flatness of the hot plate as a mathematical function}

It is difficult to determine the final value of the roll gap, taking into accounts all internal and external rolling factors. In some cases, for example, it is necessary to calculate the distance between the rolls at a particular point or to determine the variation of the gap over the entire length of the roll. The most convenient solution of this problem is to consider all the main cage systems, affecting the final roll gap, as a kind of mathematical function depending on the distance between the work rolls and the rolls length (or the width of the rolled metal). Simple mathematical manipulations with obtained functions allow to obtain the values of the roll gap at any point. Based on the same approach is convenient to calculate the position of the screw-down mechanism of the cage and the hydraulic cylinders position for auxiliary control systems for next pass of the metal depending on the size and compression requirements of shape and flatness of the workpiece.

To view the principle of constructing mathematical functions, put the rolling mill quarto plate mill in the coordinate system (figure 3 ). The best place for a starting point is a point of intersection of the centerline of rolling (the horizontal axis) and the middle of the roll length (the vertical axis). The distance between the $\mathrm{x}$-axis and the work rolls is the same. When the roll gap equals zero, the line of contact between the gap of the work rolls coincides with the line of rolling. This reference system is the most convenient for further calculations, as most of the rolling stand control systems operate symmetrically with respect to the axes, which greatly simplifies the derivation of formulas.

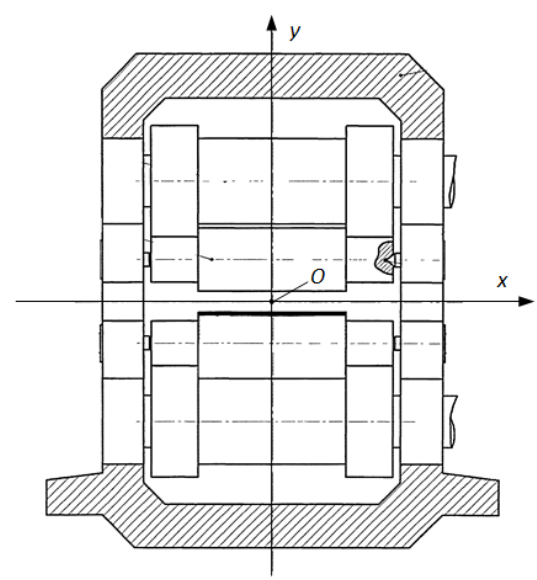

Figure 3. Quarto stand in the coordinate system

Figure 4 shows in more detail the space between the rolls and defines the basic parameters and constraints that may occur in the mathematical description. The dependence of $h(1)$ is called a "roll gap function". The distance between the rolls $\left(h_{r}\right)$ at any point is defined as the sum of the distances between the $\mathrm{x}$-axis and the rolls $\left(\mathrm{h}_{\mathrm{ur}}\right.$, $h_{b r}$ ). In this domain of the function is limited to the length of the rolls $\left(1_{r}\right)$. The domain of the function also is limited to the width of rolled metal, but in this case, the accuracy 
decreases due to elastic and plastic deformation of the whole roll.

A similar method is applicable to the rolled sheet. Before the rolling a sheet don't have a perfect rectangle shape - the thickness of the sheet in the middle and at the edges is different. A convenient way to know how to act on the work rolls during the rolling process is to pre-calculate the dependence of the sheet width and the its thickness. In this case, the key factor is the correct definition of the thickness of the sheet between passes. The system of indirect measurement of the sheet thickness allows partially compensate the flatness at the rolling moment. To accurately determine the thickness after each pass the thickness gauge is installed at the outlet of the cage that measure thickness at several points of the sheet.

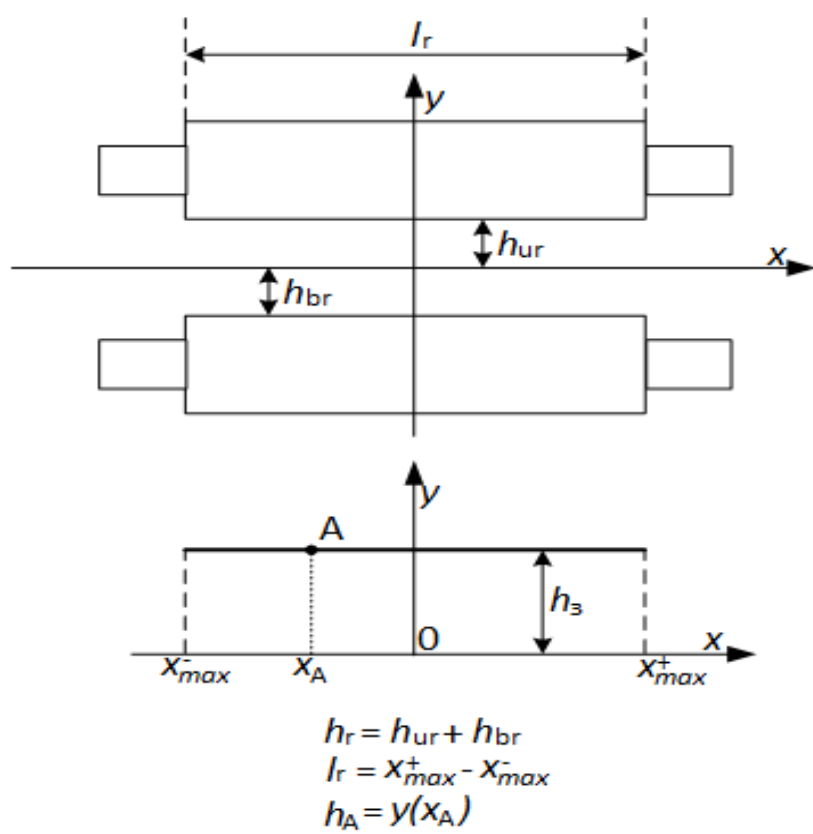

Figure 4. The roll gap as a mathematical function

Figure 5 shows an example of a local measurement of thickness in a single plane of the sheet. The thickness variation is most pronounced at the edges of the sheet, but also has a convexity in the central part of the sheet. In fact, the difference between the highest and the lowest value is usually less than a few millimeters, but in modern conditions such accuracy is insufficient to the end product.

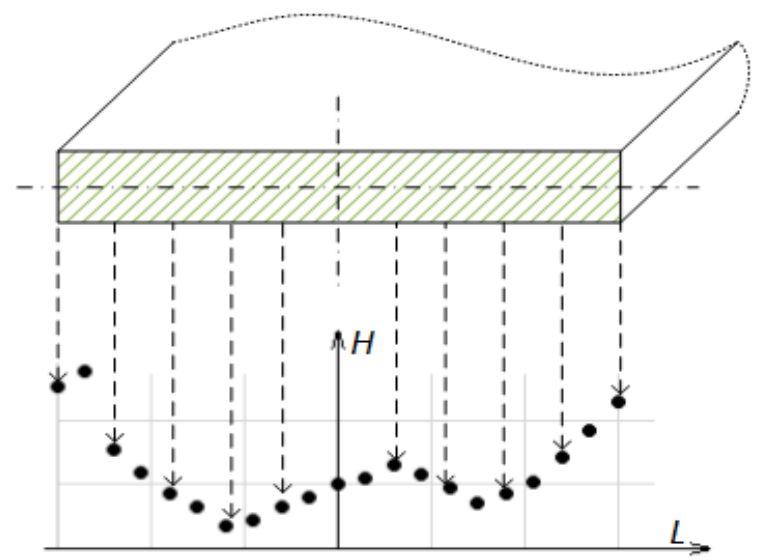

Figure 5. A measurement of the thickness at several points

To compensate for the thickness deviation the given measurements are converted into "sheet thickness function» $\mathrm{H}(\mathrm{L})$. Then the function compared with the "roll gap function" h(1) (see figure 4). Optimal conditions for compression are selected using the adjustment of the "roll gap function".

Finally, it is necessary to restore a functional relationship between the thickness and width of the sheet. To solve this problem the methods of approximation functions are used.

\section{The foundation of optimum control values for flatness systems}

Most of the hot plate mills have a thickness measurement system besides the main cage. The most useful sensors are calipers and non-contact thickness sensors. Usually after the thickness measurement and secondary signal treatment, the following array of data are possible to use:

$$
H[i, j]=\left(\begin{array}{cccc}
h_{11} & h_{12} & \ldots & h_{1 j} \\
h_{21} & h_{22} & \ldots & h_{2 j} \\
\ldots & \ldots & \ldots & \ldots \\
h_{i 1} & h_{i 2} & \ldots & h_{i j}
\end{array}\right),
$$

$H[i, j]$ is array of thickness data, $[\mathrm{mm}] ; h_{i j}$ is plate thickness at a specific point, [mm].

From the other side the same array could be received from the flatness control systems. The difference between two data arrays is a thickness deviation. Thereby the plate flatness could be minimized by changing the systems parameters. It is worth nothing that each system affects only on the part of whole plate and cannot reduce all thickness defects. Thus, it is necessary to simultaneous control of all flatness systems. The result of the system functioning is formation of the signals for local regulators of the electric and hydraulic drives at every rolling moment. It was realized by special program algorithm operating between rolling passes.

The algorithm based on the consequent calculation all the signals of each flatness system. This is caused by that some systems would operate only between rolling passes, whereas other systems work at the pass time. Moreover, the force value of main and auxiliary systems cause different impact on the metal. So there are three steps of 
algorithm can be distinguished: the first step includes the calculation of the thickness variation in each plate point. The second step contains the foundation an optimal signal value of selected flatness system. On the third step, the calculation of the new thickness array and its transfer to the next system is occurred. The algorithm repeats until all the regulator's signals will be obtained.

EGCS is the fundamental system to change the gap between the rolls. The system also used for compensate all deformations of stand and rolls.

To minimize thickness variation along the strip, the HGCS is used. The most important parameters of the system are speed of the rolls moving $[\mathrm{mm} / \mathrm{s}]$, the system performance, the reaction time, the moving value between the two adjacent thickness measurement points. The last parameter shows the value of the thickness deviation that HGCS could fully compensate (Eq. 2).

$$
\Delta l_{H G C S}=\frac{(\Delta m-V \cdot R) \cdot v}{V},
$$

$\Delta m$ is the distance between the two adjacent thickness measurement points, $[\mathrm{mm}] ; V$ is rolling speed, $[\mathrm{mm} / \mathrm{s}] ; R$ is HGCS reaction time, [s]; $v$ is max HGCS speed, [mm/s].

In case of big defect's values exceeding the maximum HGCS moving value, the system could remove all deviation only after some rolling passes.

To minimize thickness variation across the strip, the CVC-system is used [8-14]. Figure 6 shows the changing of the gap across the rolls. The reducing pressure across the strip is different, depending on the rolls offset.
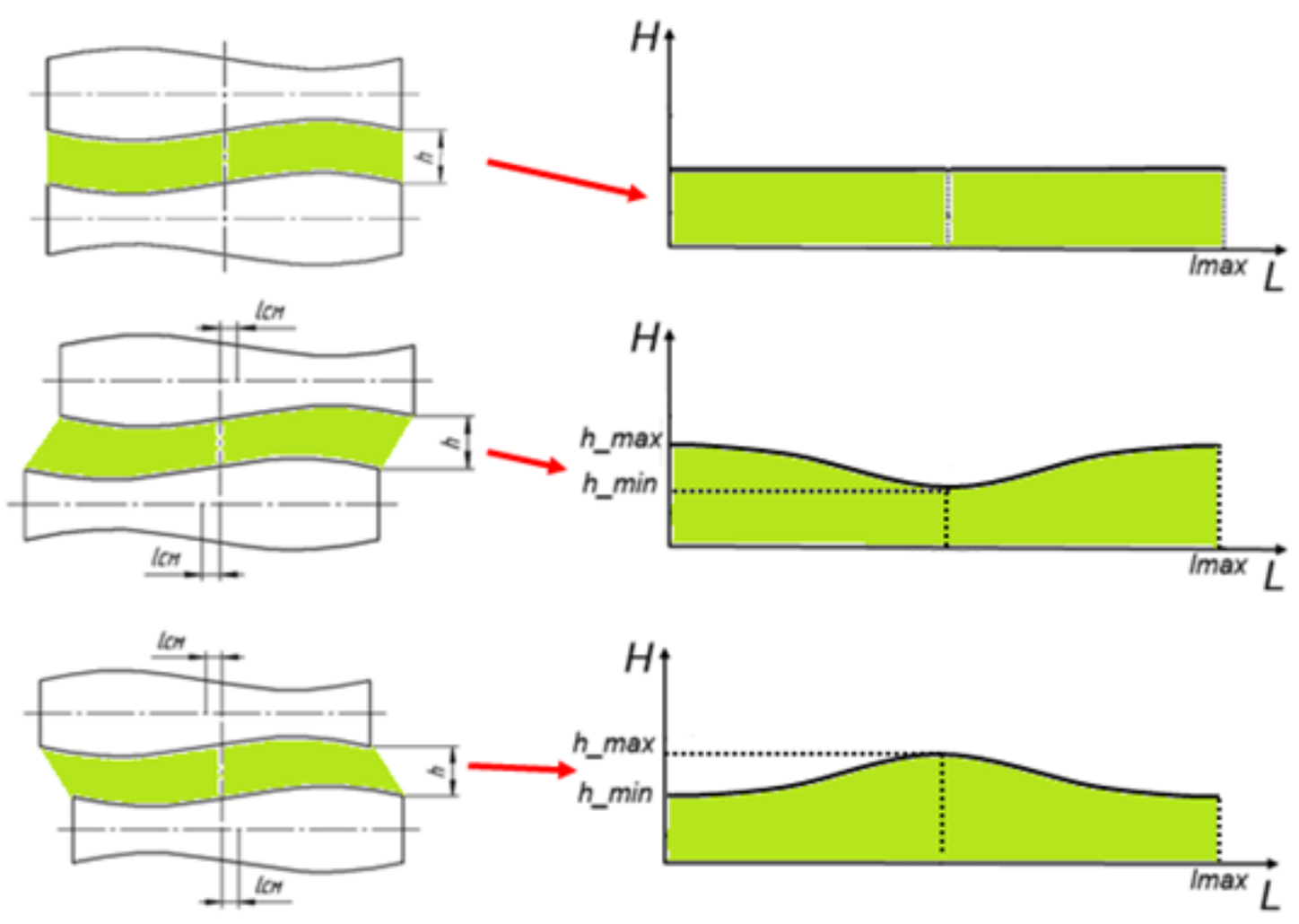

Figure 6. The influence of CVC-system shift on the roll gap (H) across the rolls (L)

The WRB-system also helps to avoid thickness variation along the strip [12]. The roll bending value could be determined based on the geometric roll parameters and rolling forces (Eq. 3).

$$
h_{W R B}(l)=\left(h_{\max A}-h_{B}\right) \cdot\left[4 \cdot\left(\frac{l}{l_{\text {roll }}}\right)^{2}-1\right],
$$

$h_{W R B}(l)$ is work roll bending function, $[\mathrm{mm}] ; h_{\max A}$ is maximum roll bending, [mm]; $h_{B}$ is WRB reaction, [mm]; $l$ is calculated point, $[\mathrm{mm}] ; l_{\text {roll }}$ is roll's length, $[\mathrm{mm}]$.

Parameter $h_{\max A}$ proportional to the force created by hydraulic cylinders and could be determined by summing all the forces of each WRB cylinders. Thickness deviation is minimized by foundation the optimal value on every section along the metal plate.

Finally, the result is presented as data massive including all system shifts and moving. Figure 7 shows how the thickness variation changes before and after system configuration. At the transverse plane the concavity of the strip is shown, that may leads to different reduction across the strip. At the longitudinal plane the convexity of the strip is observed. Thickness at the center of the sheet length is higher than at its edges. It may be possible to eliminate both defects using all flatness control systems simultaneously. 

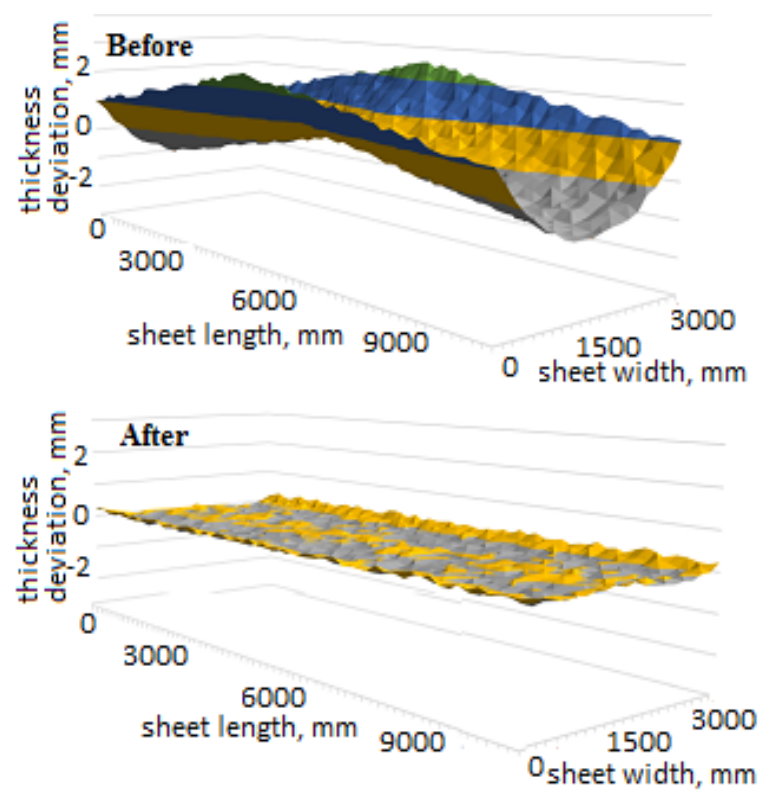

Figure 7. Three-dimensional view of thickness deviation of the hot sheet before and after rolling pass

The developed algorithm allows to eliminate defects of the sheet at the first and the last passes equally. The rough thickness irregularities are removed at the first several passes by EGCS and HGCS systems. Then at the finish passes the final flatness of the strip are formed via CVC and WRB systems. The algorithm's precision depends on the number of thickness measurements obtained from non-contact caliper.

\section{Summary}

The equipment of the rolling mills has complex structure. During development an automation system, it is necessary to examine each cage system individually and its impact on the rolling process. The designed equipment classification permit more detailed to explore the dependence between geometric dimensions of the sheet and flatness control system operating. The investigations show the flatness forming algorithm including calculations of the regulator's signals may be used for development of technological rolling schemes in the hot plate mill conditions. This will achieve the required thickness of the sheet with fewer reduction passes.

\section{References}

1. V. R. Gasiyarov, O. A. Zalogin, A. A. Radionov, "The strip thickness, profile and flatness control systems of the Magnitogorsk steel works hot plate mill 5000," Urals science and industry. pp. 107-112, (2010)

2. N. N. Druzhinin, Continuous rolling mills as an automatiozation objects. (1975)

3. V. R. Gasiyarov, D. U. Usatiy, "The thickness control system of the hot plate mill 5000," Technology and production automation processes in metallurgy. pp. 126-130, (2012)

4. S. S. Voronin, D. U. Usatiy, "A variable compression slab technology in the vertical and horizontal rolling cages of the hot plate mills," Actual problems of modern science, technology and education. 71, (2013)

5. D. N. Popov, Dynamics and regulation of hydraulic and pneumatic systems. (1976)

6. V. R. Gasiyarov, A. A. Radionov, L. V. Radionova, D. U. Usatiy, "Automatic control of the geometry of the hot plate rolling mill 5000," All-Russian multiconference on control problems. 4, pp. 307-309, (2011)

7. S. S. Voronin, D. U. Usatiy, "Work roll bending as a parameter that affects the lateral variation in thickness of the sheet and work roll bending control system of the hot rolling mill," Russian Internet Journal of Industrial Engineering. 1, pp. 51-55, (2013). URL: $\mathrm{http}$ ://www.indust-engineering.ru

8. S. S. Voronin, D. U. Usatiy, V. R. Gasiyarov, A. A. Radionov, The using of the CVC system to improve the roll gap on the hot rolling plate mills, Russian Internet Journal of Industrial Engineering. 1, pp. 45-49, (2015). URL: http://www.indust-engineering.ru

9. Radionov, A.A., Gasiyarov, V.R., Gasiyarova, O.A., Automatic gap control of Plan View Pattern Control Mechatronics System, Source of the Document 2015 International Siberian Conference on Control and Communications, SIBCON 2015 - Proceedings, pp. $1-4$.

10. Radionov, A.A., Maklakov, A.S., Gasiyarov, V.R., Smart Grid for main electric drive of plate mill rolling stand, Proceedings of 2014 International Conference on Mechanical Engineering, Automation and Control Systems, MEACS 2014, pp. 1-4.

11. Karandaev, A.S., Radionov, A.A., Khramshin, V.R., Andryushin, I.Y., Shubin, A.G., Automatic gauge control system with combined control of the screw-down arrangement position, 2014 12th International Conference on Actual Problems of Electronic Instrument Engineering, APEIE 2014 Proceedings, pp. 88-94.

12. Shilyaev, P.V., Andryushin, I.Yu., Golovin, V.V., Radionov, A.A., Karandaev, A.S., Khramshin, V.R., Algorithms of a digital automatic system for tension and loop control in a wide-strip hot-rolling mill, Russian Electrical Engineering. 84 (10), pp. 533-541

13. A.S. Maklakov, A.A. Radionov, Proceedings of the 2015 IEEE North West Russia Section Young Researchers in Electrical and Electronic Engineering Conference, ElConRusNW 2015, 236-240 (2015)

14. A.A. Radionov, A.S. Maklakov, E.A. Karyakina, Proceedings 2015 International Siberian Conference on Control and Communications, SIBCON 2015, (2015). 